\title{
O-Methylthreonine, a New Bleaching Agent for Euglena gracilis
}

\author{
BY S. AARONSON AND BARBARA BENSKY \\ Haskins Laboratories, Nero York 17, N.Y. and Biology Department, Queens \\ College, Flushing 67, N.Y.
}

(Received 24, April 1961)

\section{SUMMARY}

$O$-Methylthreonine (OM) inhibits multiplication and photosynthetic pigment synthesis in Euglena gracilis and Ochromonas danica; it does not inhibit Chlamydomonas reinhardi or Rhodopseudomonas palustris. Inhibition of multiplication and pigment synthesis may be prevented by L-isoleucine. OM also causes the permanent loss of chlorophyll and appreciable loss of carotenoids in $E$. gracilis and this may be prevented by L-isoleucine, $\alpha$-aminobutyric acid, $\alpha$-ketobutyric acid, L-threonine, L-homoserine, or L-methionine. $\alpha$-Ketobutyric acid is most effective on a molar basis and is therefore postulated to be the target of OM inhibition.

Isoleucine plays a role in the biosynthesis of photosynthetic pigments and lipids in Euglena gracilis, for the incorporation of ${ }^{14} \mathrm{C}-\mathrm{L}$-isoleucine radioactivity into both the pigments and lipids is markedly diminished by bleaching agents which prevent pigment synthesis without affecting multiplication, i.e. $O$-methylthreonine or streptomycin. When pigment synthesis is blocked amino acids accumulate in the culture supernate.

\section{INTRODUCTION}

Many chlorophyll-containing organisms have been bleached temporarily by an assortment of chemical and physical agents (Scher \& Aaronson, 1958; Aaronson \& Scher, 1960) but only the phytoflagellate, Euglena gracilis, has been rendered permanently apochlorotic-that is, free of chlorophyll and capable of multiplication-by chemical agents such as streptomycin (Provasoli, Hutner \& Schatz, 1948; Jirovec, 1949) and antihistamines (Gross, Jahn \& Bernstein, 1955) and physical agents such as heat (Pringsheim \& Pringsheim, 1952) and ultraviolet irradiation (Pringsheim, 1958). This phenomenon of apochlorosis is one of the few instances where a change in the environment results in a specific, permanent, inherited change in the phenotype of an organism. Other specific environmentally induced and heritable changes such as bacterial transformation, transduction, or killer factor in Paramecium, unlike Euglena bleaching, involve the transfer of nucleic acids or particles such as a bacteriophage or killer factor containing nucleic acids. In apochlorosis in $\boldsymbol{E}$. gracilis diverse agents operating in unknown ways affect the same site-the synthesis of chlorophyll, of the plastid or both. We do not know how any of these agents function to produce apochlorosis.

Recently we were fortunate in obtaining DL-O-methylthreonine (OM, also called $\beta$-methoxythreonine) which inhibited multiplication and pigment synthesis of Euglena gracilis and several metaphyta; this inhibition was annulled by isoleucine 
(Gray \& Hendlin, 1956). We have confirmed these observations and have shown that OM renders $E$. gracilis permanently apochlorotic and that $\alpha$-ketobutyrate or amino acids that can be metabolized to $\alpha$-ketobutyrate prevent bleaching by OM. We also have shown that isoleucine is involved in the synthesis of photosynthetic pigments and lipids.

\section{METHODS}

The organisms used were the phytoflagellates Euglena gracilis var. Z, Ochromonas danica, Chlamydomonas reinhardi, and the photosynthetic bacterium Rhodopseudomonas palustris.

The chemically defined media and the procedures for the growth of these organisms were described elsewhere (Aaronson \& Scher, 1960). Multiplication was measured as optical density (OD) with a Welch Densichron (Chicago, Illinois, U.S.A.). Photosynthetic pigments were routinely determined by the extraction of organisms with 3-5.0 ml. portions of methanol; these were pooled and the concentration of pigments assayed by reading the OD with Klett-Summerson colorimeter using the 42 (400$500 \mathrm{~m} \mu)$ and $66(640-700 \mathrm{~m} \mu)$ filters.

Mass culture of organisms permanently bleached by DL-O-methylthreonine (OM), streptomycin, or an incubation temperature of $35.5^{\circ}$ were grown in chemically defined media at $25^{\circ}$ in the light. Pigments were extracted by a variation of the aforementioned method and the supernatant fluids prepared by centrifuging the organisms, filtering the supernatant fluids and concentrating it 10-40-fold by reduced pressure distillation. The concentrated supernatant fluids were examined for porphyrins and nucleic acid derivatives with the Beckman DU spectrophotometer. The supernatant fluids were also examined for nucleic acid derivatives by ascending paper chromatography on Whatman No. 1 paper with a butanol + acetic acid + water $(4+1+5, \mathrm{v} / \mathrm{v})$ solvent system. Amino acids were assayed by adding $1.0 \mathrm{ml}$. of culture supernatant fluid to a mixture of $1.0 \mathrm{ml}$. of a solution of $0.5 \mathrm{~g}$. ninhydrin/ $100 \mathrm{ml}$. acetone, and $3.0 \mathrm{ml}$. water. This mixture was heated for $5 \mathrm{~min}$. at $90^{\circ}$ and the OD read on the Klett-Summerson colorimeter with the $54(520-580 \mathrm{~m} \mu)$ filter.

Supernatant fluids were examined for amino acids by both ascending and descending paper chromatography on Whatman No. 1 paper with the following solvent systems: isopropanol + acetic acid + water $(7+2+1, v / v) n$-butanol + acetic acid + water $(12+3+5, v / v)$ or methanol + pyridine + water $(80+4+20, v / v)$. Amino acids were developed by dipping the paper in a solution of $0.2 \mathrm{~g}$. ninhydrin/ $100 \mathrm{ml}$. acetone, air-drying the paper, and heating $5 \mathrm{~min}$. at $90-100^{\circ}$. Photosynthetic pigments were separated by the method of Strain (1953), with Whatman No. 1 paper soaked in $10 \%(\mathrm{v} / \mathrm{v})$ glycerol in methanol, air-drying the paper, and developing pigments in $0.5 \mathrm{~g} . n$-propanol in $100 \mathrm{ml}$. of light petroleum. Pigment spots were identified by their fluorescence or absorption when exposed to Wood's light.

Radioactivity was determined with a Nuclear-Chicago scaler with a model D 47 gas flow Micromil window counter (Nuclear-Chicago, Inc., Chicago 45, Illinois, U.S.A.).

Uniformly-labelled ${ }^{14} \mathrm{C}$-L-isoleucine was purchased from Schwarz Laboratories, Inc. (Mount Vernon, New York, U.S.A.).

We are indebted to Dr D. Hendlin of the Research Laboratories of Merck Sharp and Dohme, Inc. (Rahway, New Jersey, U.S.A.) for calling our attention to the effect of OM on Euglena and a generous gift of this compound. 
The bleached and normal organisms were examined with (i) a Zeiss Lumipan microscope equipped for phase, darkfield, and polarized light microscopy through the kind co-operation of Dr J. J. Lee (Dept. of Micropaleontology, American Museum of Natural History, New York, New York, U.S.A.); (ii) a Zeiss standard microscope GFL equipped for fluorescent microscopy with a Reichert 'Fluorex' maximumpressure mercury-vapour arc-light source, type $\mathrm{HBO200}$, through the courtesy of Messrs H. A. Fischer and D. Amsterdam of the Isaac Albert Research Institute of the Jewish Chronic Disease Hospital, Brooklyn, New York, U.S.A.

\section{Effect of OM on multiplication}

\section{RESULTS}

OM inhibited multiplication of several photosynthetic flagellates (Tables 1, 2). Ochromonas danica was at least ten times more sensitive than Euglena gracilis. The photosynthetic bacterium, Rhodopseudomonas palustris, and the phytoflagellate, Chlamydomonas reinhardi, were not inhibited by $\mathrm{OM}$ up to concentrations of $30.0 \mathrm{mg} .1$ $100 \mathrm{ml}$. The inhibition of multiplication of $O$. danica and $E$. gracilis was annulled by isoleucine; this prevention of inhibition was competitive. The partial inhibition of $\boldsymbol{E}$. gracilis multiplication by $\mathrm{OM}$ was also annulled by several other amino acids, aliphatic acids, and certain steroids and their precursors. These were not examined in detail because of the limited supply of OM.

Table 1. Effect of $O M$ on multiplication and pigment synthesis of $O$. danica

\begin{tabular}{|c|c|c|c|c|c|c|}
\hline \multirow{3}{*}{$\begin{array}{c}\text { Concentration } \\
\text { (mg. \%, w/v) } \\
\text { O-Methylthreonine } \\
\text { (OM) }\end{array}$} & \multicolumn{6}{|c|}{ Optical density (as \% of normal) } \\
\hline & \multicolumn{3}{|c|}{ No isoleucine } & \multicolumn{3}{|c|}{ DL-isoleucine $3.0 \mathrm{mg} \cdot \%, \mathrm{w} / \mathrm{v}$} \\
\hline & Cell & $660 \mathrm{~m} \mu$ & $420 \mathrm{~m} \mu$ & Cell & $660 \mathrm{~m} \mu$ & $420 \mathrm{~m} \mu$ \\
\hline $0 \cdot 6$ & 103 & 86 & 80 & 100 & 107 & 100 \\
\hline $1 \cdot 0$ & 66 & 29 & 23 & 100 & 105 & 100 \\
\hline $\mathbf{2 \cdot 0}$ & 20 & 8 & 6 & 103 & 100 & 100 \\
\hline 4.0 & 5 & - & - & 103 & 82 & 100 \\
\hline
\end{tabular}

Effect of OM on photosynthetic pigment formation in Euglena gracilis

When grown in $O M$ at concentrations between about 1.0 and $10.0 \mathrm{mg} . / 100 \mathrm{ml}$., there was no marked inhibition of multiplication but the resulting suspension of organisms was white and the organisms contained little if any carotenoids and no chlorophyll (Table 2). When samples of these organisms were plated on inhibitorfree agar media the resulting colonies were white and successive weekly transfers of the progeny of these colonies (33rd at this writing) in the light remained white, i.e. permanently apochlorotic. Extraction of the photosynthetic pigments of these white organisms revealed no chlorophyll; however, in the absence of OM, carotenoids were synthesized but only $4 \%$ of the normal quantity. Similar low quantities of carotenoids were found in dark-grown organisms or organisms bleached by streptomycin or high temperature $\left(35.5^{\circ}\right)$ incubation.

Bleaching of Euglena gracilis

Bleaching by OM was competitively annulled by L-isoleucine, L-threonine, Lhomoserine, $\alpha$-aminobutyric acid or $\alpha$-ketobutyric acid; $\alpha$-ketobutyric acid was most 


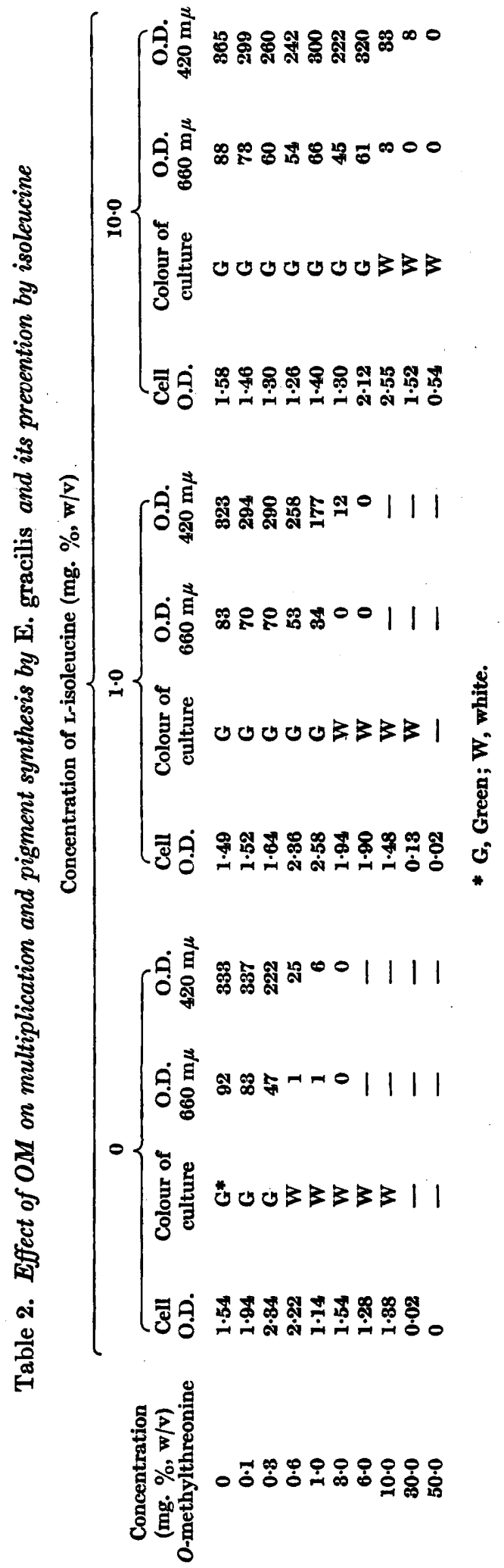


Table 3. Compounds preventing the bleaching of $\mathbf{E}$. gracilis by DL-O-methylthreonine $(O M)$

Compound<smiles>COC(C)C(N)C(=O)O</smiles>

DL-O-methylthreonine

$\mathrm{CH}_{\mathbf{3}}$ - $\mathrm{CH}_{\mathbf{2}}$-CH-CH-COOH<smiles>CCN</smiles>

L-isoleucine

0.23<smiles>CC(O)C(N)C(=O)O</smiles>

L-threonine

$\mathrm{CH}_{2} \mathrm{OH}-\mathrm{CH}_{2}-\mathrm{CH}-\mathrm{COOH}$<smiles>[NH3+]</smiles>

L-homoserine

0.50<smiles>CCC(N)C(=O)O</smiles>

$\alpha$-aminobutyric acid

$0 \cdot 29$<smiles>CCC(=O)C(=O)O</smiles>

$\alpha$-ketobutyric acid

$0 \cdot 1$
Conc. (in mM) needed

to prevent bleaching by $0.23 \mathrm{mM}$ of $\mathrm{OM}$

Table 4. Effect of isomers of threonine on OM inhibition of Euglena

\begin{tabular}{|c|c|c|c|}
\hline \multirow{2}{*}{\multicolumn{2}{|c|}{$\begin{array}{l}\text { Compound concentration } \\
(\mathrm{mg} . \% \mathrm{w} / \mathrm{v})\end{array}$}} & \multicolumn{2}{|c|}{$\begin{array}{l}\text { Concentration of } \mathrm{OM} \\
(\mathrm{mg} . \% \mathrm{w} / \mathrm{v})\end{array}$} \\
\hline & & \multicolumn{2}{|c|}{$\begin{array}{l}1.0 \\
\text { optical density }\end{array}$} \\
\hline & 0 & $2 \cdot 18 W^{*}$ & $1.42 \mathrm{~W}^{*}$ \\
\hline D-threonine & $\begin{array}{r}1 \cdot 0 \\
8 \cdot 0 \\
6 \cdot 0 \\
10 \cdot 0\end{array}$ & $\begin{array}{l}2 \cdot 42 \mathrm{~W} \\
\mathbf{2 \cdot 6 2} \mathrm{W} \\
\mathbf{2 \cdot 3 2} \mathrm{W} \\
\mathbf{2 \cdot 4 0} \mathrm{W}\end{array}$ & $\begin{array}{l}1.66 \mathrm{~W} \\
1.94 \mathrm{~W} \\
1.60 \mathrm{~W} \\
1.68 \mathrm{~W}\end{array}$ \\
\hline L-threonine & $\begin{array}{r}1.0 \\
8.0 \\
6.0 \\
10 \cdot 0\end{array}$ & $\begin{array}{l}2 \cdot 12 \mathrm{~W} \\
2 \cdot 60 \mathrm{G} \\
2 \cdot 48 \mathrm{G} \\
2 \cdot 54 \mathrm{G}\end{array}$ & $\begin{array}{l}1.28 \mathrm{~W} \\
\mathbf{2} \cdot 08 \mathrm{~W} \\
\mathbf{2 . 2 6} \mathrm{G} \\
\mathbf{2 . 5 8} \mathrm{G}\end{array}$ \\
\hline
\end{tabular}

W, White colour of cell suspension; $G$, green colour of cell suspension. 
effective on a molar basis (Table 3). Bleaching by OM was also annulled by Lmethionine and tiglic acid (an intermediate in isoleucine synthesis) and by crotonic acid; these also suppress multiplication at higher concentrations and are therefore not very effective as anti-bleaching agents. The $D$-isomers of the above amino acids did not prevent the bleaching by OM, e.g. D-threonine (Table 4). They did, however, partially prevent the inhibition of multiplication by OM (Table 5). Mixtures of

Table 5. Effect of some chemicals on the multiplication and ability to prevent $O M$ bleaching of $\mathbf{E}$. gracilis

\section{Compound}

Acetic acid

3-Acetyl-butyric acid cis-Aconitic acid

Adipic acid

$\alpha$-Amino-adipic acid

$\alpha$-Amino-butyric acid

DL- $\beta$-Amino- $n$-butyric acid

$\gamma$-Amino-butyric acid

$\delta$-Amino-levulinic acid

8-Amino- $n$-valeric acid

Butyric acid

2-Carboxy-butyric acid

Citric acid

Crotonic acid

2,4-Diamino-butyric acid

DL-Diethylmalate

Dimethylmalonate

Ethyl-2-hydroxy-butyric acid

Ethyl-lactate

Fumaric acid

8-Hydroxy-butyric acid

2-Hydroxy-isobutyric acid

$\alpha$-Hydroxy- $\alpha$-methyl-butyric acid

$\beta$-Hydroxy- $\beta$-methyl-glutaric acid

3-Hydroxypropionic acid

Isobutyric acid

L-Isocitric acid

Isovaleric acid

$a$-Keto- $n$-butyric acid

$\alpha$-Ketoglutaric acid

$\beta$-Ketoglutaric acid

$\beta$-Ketoglutaric acid, dimethyl ester

$\alpha$-Keto-isovaleric acid

Lactic acid

Malic acid

8-Methoxybutyric acid

DL- $\alpha$-Methyl- $n$-butyric acid

$\beta$-Methyl-glutaric acid

Methylmalonic acid

$\alpha$-Methyl- $n$-valeric acid

$\beta$-Methyl- $n$-valeric acid

$\gamma$-Methyl- $n$-valeric acid

Oxalacetic acid

Propionic acid

Succinic acid

Tiglic acid
Highest conc. studied

(mg. \% w/v or v/v)

Organic acids

100

10

10

10

10

10

10

10

10

10

10

10

10

10

10

100

10

10

10

10

10

10

30

10

10

10

10

10

10

10

10

100

10

10

100

10

10

30

10

10

50

10

100

10

10
Effect on multiplication

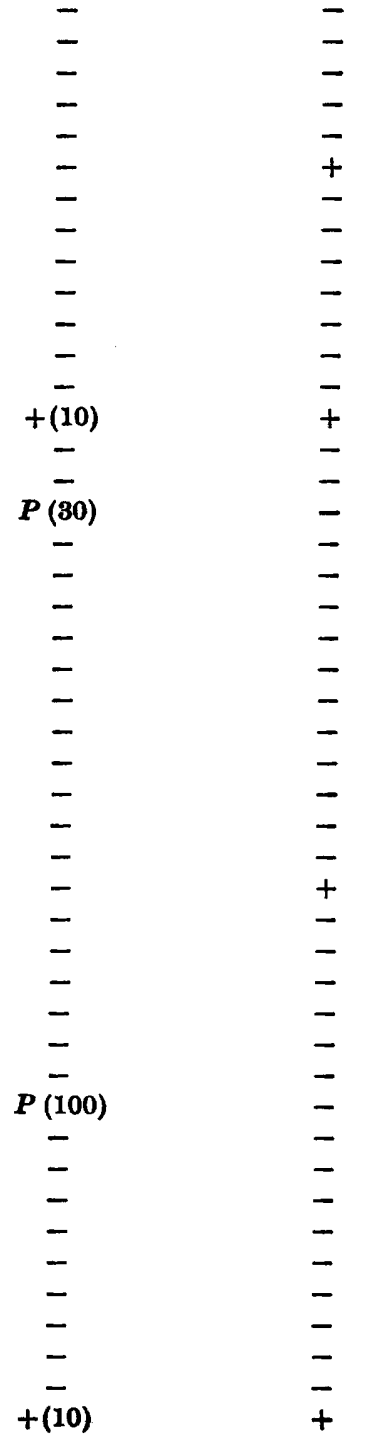

Ability to prevent bleaching by $\mathrm{OM}$ 
Table 5 (cont.)

Highest conc.

\section{Compound}

D-Alloisoleucine
DL-Allothreonine
Asparagine
Aspartic acid
L-Cysteine
L-Glutamic acid
L-Glutamine
Glycine
L-Homoserine
L-Isoleucine
D-Isoleucine
L-Leucine
D-Leucine
DL-Methionine
$\beta$-Methylaspartic acid
O-Methylthreonine
DL-Norleucine
DL-Norvaline
DL-Serine
L-Threonine
D-Threonine
L-Valine
D-Valine
1-Amino-2-propanol
3-Amino-propanol
2-Amino-2-methyl-propanol
Cyclopentylamine
$\beta$-Mercaptoethanol
2-Methyl-butylamine
Pyridoxamine
Threamine
C-Sitosterol
Cholesterol
Ergosterol
Farnesol
Geraniol
Isoprene
Lanosterol
Mevalonic acid lactone

\author{
studied
}

(mg. $\% \mathrm{w} / \mathrm{v}$ or $\mathrm{v} / \mathrm{v}$ )

Amino acids

165

10

10

10

10

50

50

100

10

110

10

110

110

10

10

50

330

150

10

100

100

100

100

Alcohols and amines

10
10
10
100
100
10
10
10

Sterols and sterol precursors
Effect on multiplication

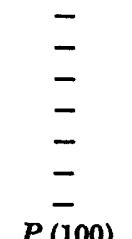

$P$ (100)

$\boldsymbol{P}(66)$

P (110)

$P$ (66)

$P$ (10)

$+\overline{(30)}$

$P$ (11)

$P$ (20)

$P$ (30)

$\boldsymbol{P}$ (30)

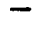

Ability to prevent bleaching by $O M$

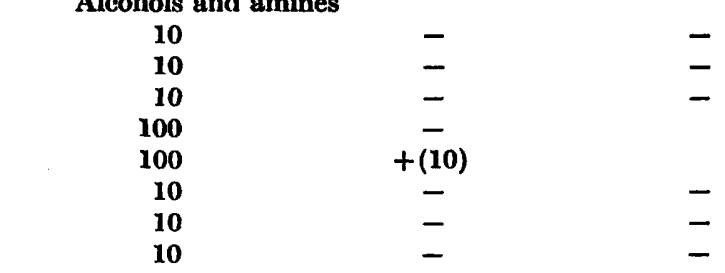

* $+(10)$ conc. in mg. which cause complete inhibition. $P(10)$ conc. in $\mathrm{mg} . \%$ which causes partial inhibition.

amino acids, water-soluble vitamins, $\mathrm{NH}_{4} \mathrm{Cl}$, succinic acid and glycine, alone or together did not prevent the bleaching by OM.

The supernatant fluids of cultures bleached by OM, streptomycin or heat contained large quantities of amino acids. Neither these nor the supernatant fluids from normal cultures grown in the light or in the dark and concentrated 10 times prevented bleaching by OM when used in the range 0.01-10.0\% (v/v). These same supernatant 
fluids in the above concentration range as well as the amino acids and keto acids which prevented OM-bleaching failed to re-green OM-bleached organisms.

We examined the bleaching ability of several compounds that resembled the branched-chain amino acids as well as compounds reported to inhibit isoleucine synthesis, e.g. penicillamine inhibition of Escherichia coli is prevented by isoleucine, valine or leucine (Aposhian, Blair, Morris \& Smithson. 1959). Mercaptoethanol was included because Brachet (1958) reported that it decreased the size of algal chloroplasts. None of these compounds prevented bleaching by OM nor did they act as bleaching agents themselves; some inhibited multiplication (Table 5).

\section{Microscopic examination of permanently bleached Euglena gracilis}

Organisms from cultures of Euglena gracilis permanently bleached by OM, streptomycin, or elevated incubation temperature $\left(35.5^{\circ}\right)$ were compared with normal green organisms by ordinary light, phase, dark field, fluorescent and polarized light microscopy. No differences in number or appearance of intracellular bodies in any of the bleached organisms were noted; the 'eye spot' was present in all. Pringsheim (1941) noted that incubation for extended periods in the dark was necessary for the disappearance of the eye spot in bleached organisms; our cultures were maintained in the light.

The sole difference noted between bleached organisms and normal green ones was the disappearance of the green colour and absence of the red fluorescence of chlorophyll. Some of the colourless bodies seen in the bleached organisms contained oriented internal structures when examined under polarized light.

Table 6. Effect of $O M$ on cell and pigment synthesis and the accumulation of amino acids

Cells were grown for this experiment in $100 \mathrm{ml}$. volumes in $500 \mathrm{ml}$. screw-top flasks in light.

\begin{tabular}{|c|c|c|c|c|c|c|}
\hline \multirow{2}{*}{\multicolumn{2}{|c|}{$\begin{array}{c}\text { Compound } \\
\text { (mg./100 ml. water) }\end{array}$}} & \multirow[b]{2}{*}{$\begin{array}{l}\text { Cell } \\
\text { O.D. }\end{array}$} & \multirow[b]{2}{*}{$\begin{array}{l}\text { Colour of } \\
\text { culture }\end{array}$} & \multicolumn{2}{|c|}{ O.D. at } & \multirow{2}{*}{$\begin{array}{l}\text { Approx. conc. of } \\
\text { amino acids in } \\
\text { supernate } \\
\text { (mg./ml.) }\end{array}$} \\
\hline & & & & $660 \mathrm{~m} \mu$ & $\overline{420 \mathrm{~m} \mu}$ & \\
\hline $\mathbf{O M}$ & $\begin{array}{r}0 \\
1 \\
10\end{array}$ & $\begin{array}{l}2 \cdot 22 \\
1 \cdot 20 \dagger \\
1 \cdot 18 \dagger\end{array}$ & $\begin{array}{l}\text { Green } \\
\text { White } \\
\text { White }\end{array}$ & $\begin{array}{r}303 \\
6 \\
5\end{array}$ & $\begin{array}{r}1000 \\
57 \\
69\end{array}$ & $\begin{array}{l}0 * \\
0.008 \\
0.02\end{array}$ \\
\hline $\mathbf{O M}$ & $\begin{array}{r}1+\text { L-isoleucine } 10 \\
10+\mathrm{L} \text {-isoleucine } 10\end{array}$ & $\begin{array}{l}2.46 \\
0.92 \dagger\end{array}$ & $\begin{array}{l}\text { Green } \\
\text { White }\end{array}$ & $\begin{array}{r}800 \\
7\end{array}$ & $\begin{array}{r}1000 \\
91\end{array}$ & $\begin{array}{l}0 \\
0 \cdot 166\end{array}$ \\
\hline
\end{tabular}

\section{Supernatant fuids of bleached Euglena cultures}

The supernatant fluids of experimental cultures in which $\mathrm{OM}$ had induced bleaching contained large quantities of amino acids. There were no amino acids in the supernatant fluids of cultures grown without OM or not bleached by OM. Supernatant fluids of cultures in which isoleucine had prevented the bleaching by $O M$ and whose organisms remained green contained only small quantities of isoleucine (Table 6). When organisms permanently bleached by OM, streptomycin, or heat were 
grown in a chemically defined medium in the absence of bleaching agents and the supernatant fluids concentrated and chromatographed, large quantities of amino acids also were found in the culture fluids; more amino acids appeared in the culture fluids of streptomycin and heat-bleached than in OM-bleached supernatant fluids.

That some of this accumulated amino-acid material reflects lack of isoleucine utilization is shown by the appearance of radioactivity in amino acids other than isoleucine that accumulate when pigment synthesis is blocked (Table 7).

Table 7. Effect of bleaching agents on the incorporation of ${ }^{14} \mathrm{C}$-isoleucine

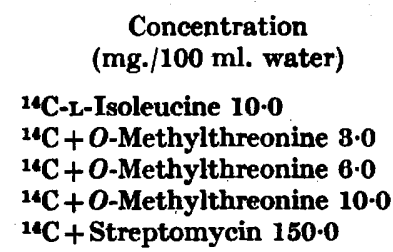

Concentration
(mg./100 ml. water)

${ }^{14} \mathrm{C}$-L-Isoleucine 10.0

${ }^{14} \mathrm{C}+$ Streptomyein $150 \cdot 0$

* $22 \%$ of total radioactivity in methanol extract appeared in pigments (carotenoids and chlorophyll).

$\dagger 11 \%$ of total radioactivity in supernate appeared in amino acids other than isoleucine.

This amino-acid accumulation presumably results from the cessation of protein synthesis in the chloroplast or the cessation of pigment synthesis. To decide which, organisms were grown in uniformly labelled ${ }^{14} \mathrm{C}$-L-isoleucine, with and without bleaching agents (Table 7). Usually about $45 \%$ of the radioactivity incorporated from isoleucine appeared in the methanol extract containing photosynthetic pigments and other lipids. Bleaching concentrations of agents that bleach, i.e. OM or streptomycin, decreased the incorporation of ${ }^{14} \mathrm{C}$-isoleucine into the organisms, $12 \%$ for $\mathrm{OM}$ and $15 \%$ for streptomycin. Incorporation of ${ }^{14} \mathrm{C}$-isoleucine into the methanol extract, which we assume to include photosynthetic pigments as well as many lipids, was reduced $62 \%$ by $\mathrm{OM}$ and $50 \%$ by streptomycin.

Multiplication and hence protein synthesis continued in the presence of bleaching concentrations of $\mathrm{OM}$ or streptomycin and incorporation of ${ }^{14} \mathrm{C}$-isoleucine into the cells was relatively slightly depressed while there was a $50 \%$ or greater decrease in the incorporation of ${ }^{14} \mathrm{C}$-isoleucine into the pigments and lipids of bleached organisms (Table 7).

Chromatography of the methanol extract of green cells revealed that about $22 \%$ of the total radioactivity was in chlorophylls and carotenoids.

Where synthesis of chlorophyll is prevented, several workers (Lascelles, 1955; Larsen, 1952) have reported the appearance of porphyrins in the supernatant fluids; none were detected in the supernatant fluids of any of the bleached organisms studied here.

Escherichia coli partially inhibited by streptomycin accumulated quantities of nucleic acid derivatives (Roth, Amos \& Davis, 1960), and it has been suggested that streptomycin impaired the permeability of the cell membrane in this organism (Anand \& Davis, 1960). Examination of the supernatant fluids of cultures of norma] dark, light-grown, and permanently bleached Euglena revealed $9.0 \mu \mathrm{g} . / \mathrm{ml} .260 \mathrm{~m} \mu-$ 
absorbing material in light-grown, $11 \mu \mathrm{g} . / \mathrm{ml}$. in dark-grown, $15 \mu \mathrm{g} . / \mathrm{ml}$. in OMbleached, $15 \mu \mathrm{g} . / \mathrm{ml}$. in streptomycin-bleached, and $13 \mu \mathrm{g} . / \mathrm{ml}$. in heat-bleached Euglena. There was no marked impairment of permeability to nucleic acids or their derivatives in bleached organisms.

\section{DISCUSSION}

$O$-Methylthreonine killing of leaves of bean, pepper, tobacco, wheat, and tomato was prevented by the simultaneous addition of 2-5 times more isoleucine than $\mathrm{OM}$ but not of threonine, serine, leucine, norleucine, or valine. Inhibition of growth and chlorophyll formation in Euglena gracilis by OM was prevented by isoleucine and partially prevented by leucine and norleucine (Gray \& Hendlin, 1956). We have confirmed their results that inhibition of $\boldsymbol{E}$. gracilis by OM was competitively prevented by isoleucine. Similar results were also obtained with Ochromonas danica.

Goodwin \& Jamikorn (1954) reported a decrease in multiplication and carotenoid synthesis in dark-grown and streptomycin-containing (bleached) Euglena gracilis cultures as compared with light-grown cultures. Gross et al. (1955) found little chlorophyll in dark-grown and none in streptomycin- or pyribenzamine-bleached cells while the carotenoid content of dark-grown and streptomycin-bleached was about twice that of pyribenzamine-bleached cells; the colourless euglenid Astasia longa had no carotenoids or chlorophyll. Some workers have reported no chlorophyll in dark-adapted Euglena; others have reported a small quantity. This discrepancy probably depends on how long the organisms were cultured in the dark and also the amount of light exposure immediately before pigment extraction. Bleaching by $\mathrm{OM}$, as by other agents, results in absence of chlorophyll and decrease in carotenoids.

OM permanently bleached only Euglena gracilis, of the several photosynthetic organisms examined by us; this bleaching was prevented by the simultaneous addition of any one of several amino, or keto acids (Tables 3,5 ), most effectively by $\alpha$-ketobutyric acid. We may infer that $O M$ interferes with the utilization of $\alpha$-ketobutyrate in the synthesis of the photosynthetic pigments and that isoleucine or threonine are on the route to these pigments since both amino acids prevented bleaching by OM (Table 3, Fig. 1). That amino acids, particularly isoleucine, are involved in pigment synthesis may be deduced also from the incorporation of ${ }^{14} \mathrm{C}$ isoleucine into pigments (Table 7) and inhibition of this incorporation by bleaching.

Other workers noting interrelationships between amino acids and photosynthetic pigments include Huzisige, Terada, Nishimura \& Uemura (1957) who found amino acids increasing the chlorophyll content of resting cells of Euglena, and Glover, Goodwin \& Lijinsky (1951) who reported that leucine stimulated synthesis of carotenoids in Phycomyces blakesleeanus.

OM interferes with isoleucine (or more likely, its metabolic product, $\alpha$-ketobutyrate) in other kinds of organisms. Rabinovitz, Olson \& Greenberg (1955) found that OM blocked the incorporation of isoleucine into the proteins of Ehrlich ascites carcinoma, an inhibition prevented by isoleucine. $O$-Methyl-allothreonine did not affect isoleucine incorporation into carcinoma protein.

No other amino acid or organic acid studied prevented bleaching by $\mathrm{OM}$; among those tested were several precursors of chlorophyll such as $\delta$-aminolevulinic acid, and succinate alone or with glycine.

To see whether other inhibitors of isoleucine synthesis had bleaching activity for 


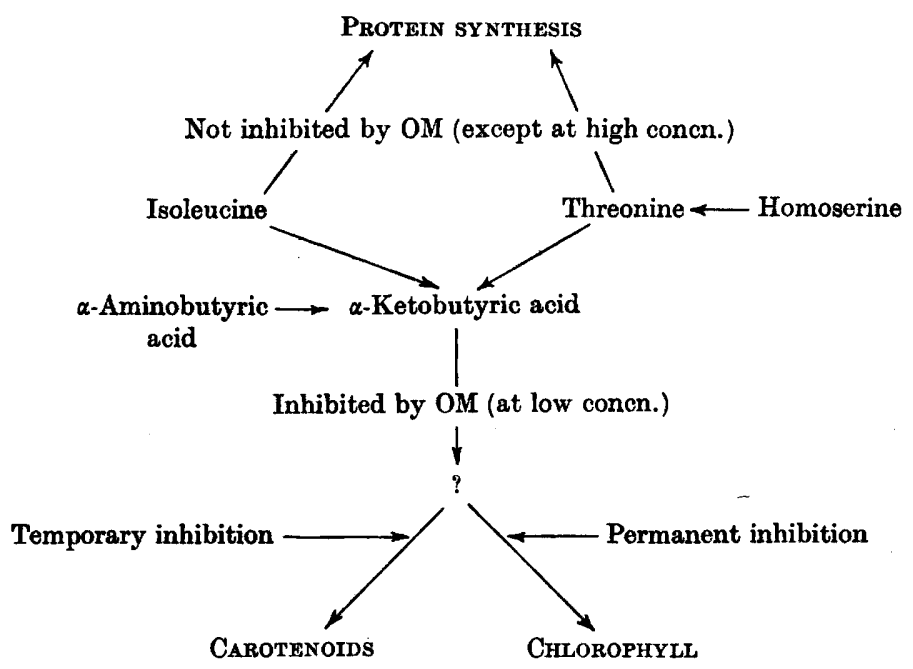

Fig. 1. Suggested sites of inhibition of Euglena gracilis by $O$-methylthreonine (OM).

Euglena gracilis we examined penicillamine which inhibited isoleucine synthesis in Escherichia coli and certain substituted cyclopentanes, one of which, cyclopentane glycine, prevented isoleucine synthesis in Escherichia coli (Harding \& Shive, 1954). None bleached.

Since Euglena does not reproduce sexually, we attempted to bleach two mating strains of Chlamydomonas reinhardi to see whether mating a bleached with a green offered information on the primary site of bleaching. Unfortunately Chlamydomonas was not bleached by OM.

Table 8. Effect of increasing $O M$ on the incidence of bleached individuals in exposed populations

\begin{tabular}{|c|c|c|c|c|c|c|}
\hline \multirow[b]{3}{*}{ Compound } & \multirow[b]{3}{*}{$\begin{array}{c}\text { Conc. } \\
(\mathrm{mg} . \% \mathrm{w} / \mathrm{v})\end{array}$} & \multirow[b]{3}{*}{$\begin{array}{l}\text { Colour of } \\
\text { culture }\end{array}$} & \multicolumn{4}{|c|}{$\begin{array}{l}\text { Appearance of colonies from sample of } \\
\text { culture when plated } \dagger\end{array}$} \\
\hline & & & \multicolumn{2}{|c|}{ No isoleucine } & \multicolumn{2}{|c|}{ Isoleucine $10.0 \mathrm{mg}$. } \\
\hline & & & $\begin{array}{c}\text { White } \\
(\%)\end{array}$ & $\begin{array}{c}\text { Green } \\
(\%)\end{array}$ & $\begin{array}{c}\text { White } \\
(\%)\end{array}$ & $\begin{array}{c}\text { Green } \\
(\%)\end{array}$ \\
\hline \multirow[t]{7}{*}{$O$-Methylthreonine } & $0 \cdot 6$ & White & 67 & $\mathbf{3 3}$ & 一 & - \\
\hline & $1 \cdot 0$ & White & 94 & 6 & - & - \\
\hline & $\mathbf{3} \cdot \mathbf{0}$ & White & 100 & $\mathbf{0}$ & - & - \\
\hline & 6.0 & White & 100 & $\mathbf{0}$ & - & - \\
\hline & $10 \cdot 0$ & White & 100 & $\mathbf{0}$ & 67 & $\mathbf{3 3}$ \\
\hline & $\mathbf{3 0 \cdot 0}$ & White & - & - & 100 & $\mathbf{0}$ \\
\hline & $50 \cdot 0$ & White & - & - & 100 & $\mathbf{0}$ \\
\hline
\end{tabular}

* No. of viable Euglena cells/ml. varied from c. 0.5-3.0 $\times 10^{\circ}$.

$\uparrow$ Samples taken from cultures shown in Table 2.

As the concentration of OM increased, the proportion of the Euglena population which showed bleaching increased to $100 \%$ (Table 8). OM selected neither for OMresistant nor bleached cells, since the growth-rates of bleached and green cultures were identical. 
Unlike most externally induced and inherited changes, OM-bleaching of Euglena is a mass phenomenon (Table 8) not clearly dependent on nucleic acid changes as are bacterial transformation, transduction or mutation. Whether this is true of other bleaching agents remains to be seen.

All organisms studicd irrespective of bleaching agent have a common feature : they accumulate large amounts of amino acids in the culture fluids, presumably as a consequence of blocked pigment synthesis. The markedly lessened incorporation of ${ }^{14} \mathrm{C}$ isoleucine into pigment and lipids in OM- and streptomycin-bleached organisms with a much smaller decrease in incorporation into proteins suggests that the amino-acid accumulation resulted from inhibition of the synthesis of plastid pigments and lipids rather than plastid proteins. Anand \& Davis (1960) found that normal Escherichia coli excreted amino acids; streptomycin treatment caused a fourfold increase in the excretion of amino acids and a greater decrease in intracellular amino acids than in intracellular nucleotides. That isoleucine figures in lipid synthesis may also be inferred from conversion by mouse adipose tissue of isoleucine to fatty acids almost as well as it so converted propionate, acetate, or methylmalonate (Feller \& Feist, 1959).

Permanent loss of chlorophyll (apochlorosis or bleaching) as a result of specific environmental changes has been reported by several authors for a few strains of Euglena gracilis; it may also occur spontaneously in nature (see review by Pringsheim, 1941 and De Deken-Grenson, 1960). No other photosynthetic organism has been rendered apochlorotic and still able to reproduce. We must note one exception: Euglena mesnili kept in the dark lose their chloroplasts permanently (Lwoff \& Dusi, 1935).

Provasoli, Hutner \& Pintner (1951) claimed the destruction of chloroplasts as well as the inhibition of chlorophyll synthesis. They observed the bleached organisms by fluorescence microscopy which permitted following the fate of the chlorophyll but told nothing of the fate of the plastids. Lwoff \& Schaeffer (1949) confirmed bleaching of Euglena gracilis by streptomycin but claimed the presence of modified plastids. Vavra (1957) claimed that streptomycin interfered with chloroplast multiplication in $E$. gracilis while De Deken-Grenson \& Messen (1958) using light microscopy, said that streptomycin lowered the chloroplast growth-rate so that apochlorotic strains developed as a result of cell multiplication outrunning chloroplast multiplication; this has been withdrawn (De Deken-Grenson \& Godts, 1960). Wolken (1956) examined by electron microscopy streptomycin- and heat-treated but no permanently-bleached Euglena; he claimed that both streptomycin and heat destroyed the chloroplast structure but his electron micrographs did not exclude a lamina-free body remaining as a vestige of the chloroplast nor do they depict the fate of the chloroplast in permanently bleached strains. The fate of the colourless chloroplast, if such exists, in apochlorotic cells remains unknown.

This investigation was supported by a grant (H-2974) from the National Institutes of Health, U.S. Public Health Service, a grant (T-76B) from the American Cancer Society; and a grant (G-9890) from the National Science Foundation. 


\section{Bleuching Euglena with O-methylthreonine}

\section{REFERENCES}

Aaronson, S. \& Scher, S. (1960). Effect of aminotriazole and streptomycin on multiplication and pigment production of photosynthetic microorganisms. J. Protozool. 7, 156.

ANand, N. \& Davis, B. D. (1960). Damage by streptomycin to the cell membrane of Escherichia coli. Nature, Lond. 185, 22.

Aposhian, H. V., Blair, R. M., Morris, M. \& Smithson, C. H. (1959). The reversal of the inhibitory activity of L-penicillamine by branched chain amino acids. Biochim. biophys. Acta, 36, 98.

Brachet, J. (1958). New observations on biochemical interactions between nucleus and cytoplasm in Amoeba and Acetabularia. Exp. Cell Res. (Suppl.), 6, 78.

de Deken-Grenson, M. (1960). Le mécanisme de la perte héréditaire d'une fonction biochimique: la synthèse des chlorophylles. Arch. Biol., Paris, 71, 271.

De Deken-Grenson, M. \& Godts, A. (1960). Descendance of Euglena cells isolated after various bleaching treatments. Exp. Cell Res. 19, 376.

de Deken-Grenson, M. \& Messin, S. (1958). La continuité génétique des chloroplastes chez les Euglènes. I. Mécanisme de l'apparition des lignées blanches dans les cultures traitées par la streptomycine. Biochim. biophys. Acta, 27, 145.

Feller, D. D. \& FeIsT, E. (1959). Metabolism of adipose tissue : incorporation of isoleucine carbon into lipids by slices of adipose tissue. J. Lipid Res. 1, 90.

Glover, J., Goodwin, T. W. \& LiJinsky, W. (1951). Studies in carotenogenesis. 2. Carotene production by Phycomyces blakesleeanus: The effect of different amino acids when used in media containing low concentrations of glucose. Biochem. J. 50, 268.

Goodwin, T. W. \& JAMIKonN, M. (1954). Studies in carotenogenesis. Some observations on carotenoid synthesis in two varieties of Euglena gracilis. J. Protozool. 1, 216.

GraY, R. A. \& Hendin, D. (1956). Inhibition of growth and chlorophyll formation in plants by $O$-methylthreonine. Plant Physiol. 31, xxi.

Gross, J. A., JAHN, T. L. \& Bennstein, E. (1955). The effect of antihistamines on the pigments of green protista. J. Protozool. 2, r1.

Harding, W. M. \& Shive, W. (1954). Cyclopentane-glycine, an inhibitory analogue of isoleucine. J. biol. Chem. 206, 401.

Huzisige, H., Terada, T., Nishimura, M. \& Uemura, T. (1957). Effect of amino acids and streptomycine on the chlorophyll formation in Euglena. Biol. Okayama Univ. 3, 209.

Jírovec, O. (1949). Ứinek antibiotik na nĕkteré prvoky. Mém. Soc. zool. tchécosl. 13, 216.

LARSEN, H. (1952). On the culture and general physiology of the green sulfur bacteria. J. Bact. 64, 187.

LAsCelles, J. (1955). The formation of porphyrins by photosynthetic bacteria. In Ciba Foundation Symposium on Porphyrin biosynthesis and metabolism, p. 268. Ed. by G. E. W. Wolstenholme \& E. C. P. Millar.

LwoFF, A. \& DusI, H. (1935). La suppression expérimentale des chloroplastes chez Euglena mesnili. C.R. Soc. biol., Paris, 119, 1092.

Lwoff, A. \& Schaeffer, P. (1949). La décoloration d'Euglena gracilis par la streptomycine. C.R. Acad. Sci., Paris, 228, 779.

Pringshem, E. G. (1941). The interrelationships of pigmented and colourless flagellata. Biol. Rev. 16, 191.

Pringsheim, E. G. (1958). Die Apoplastidie bei Euglena. Rev. Algol. 4, 41.

Pringshem, E. G. \& Pringsherm, O. (1952). Experimental elimination of chromatophores and eye-spot in Euglena gracilis. Nero Phytol. 51, 65.

Provasol, L., Hutner, S. H. \& Pintner, I. J. (1951). Destruction of chloroplasts by streptomycin. Cold Spr. Harb. Symp. quant. Biol. 16, 113.

Provasoli, L., Hutner, S. H. \& Schatz, A. (1948). Streptomycin-induced chlorophyllless races of Euglena. Proc. Soc. exp. Biol., N.Y. 69, 279.

Rabinovitz, M., Olson, M. E. \& Greenberg, D. M. (1955). Steric relationship between threonine and isoleucine as indicated by an antimetabolite study. J. Amer. chem. Soc. 77, 3109. 
Roth, H., Amos, H. \& Davis, B. D. (1960). Purine nucleotide excretion by Escherichia coli in the presence of streptomycin. Biochim. biophys. Acta, 37, 398.

Scher, S. \& AARonson, S. (1958). Nutritional factors in apochlorosis: Comparative studies with algae and higher plants. Brookhaven Symp. Biol. 11, 843.

Strain, H. H. (1958). Paper chromatography of chloroplast pigments: sorption at a liquidliquid interface. J. phys. Chem. 57, 638.

VAVRA, J. (1957). The action of streptomycin on chloroplasts of the flagellate Euglena gracilis Klebs. Folia Biol. 111, 108.

Wolken, J. J. (1956). A molecular morphology of Euglena gracilis var. bacillaris. J. Protozool. 3, 211. 